\title{
Direct Patterning of Poly(ether ether sulfone) Using a Cross-linker and a Photoacid Generator
}

\author{
By Katsuhisa MIZOGUCHI and Mitsuru UEDA*
}

A negative-type photosensitive poly(ether ether sulfone) (PSPEES) based on a commercially available engineering plastic poly(oxybiphenyl-4,4'-diyloxy-1,4-phenylenesulfonyl-1,4-phenylene) (PEES), a cross-linker 4,4'-methylenebis[2,6-bis(methoxymethyl)phenol] (MBMP) having good compatibility with PEES, and diphenylidonium 9,10-dimethoxyanthracene-2sulfonate (DIAS) as a photoacid generator (PAG) has been developed. The resist consisting of PEES ( $85 \mathrm{wt} \%$ ), MBMP $(10 \mathrm{wt} \%)$ and DIAS $(5 \mathrm{wt} \%)$ showed a high sensitivity $\left(\mathrm{D}_{0.5}\right)$ of $21 \mathrm{~mJ} / \mathrm{cm}^{2}$ and a contrast $\left(\gamma_{0.5}\right)$ of 2.1 when it was exposed to $i$-line $\left(365 \mathrm{~nm}\right.$ wavelength light), post-exposure baked (PEB) at $170{ }^{\circ} \mathrm{C}$ for $3 \mathrm{~min}$, and developed with $N, N$ dimethylacetamide (DMAc) at room temperature. A fine negative-image featuring $4 \mu \mathrm{m}$ line-and-space pattern was obtained on the film. Thus, this photolithographic system has a highly potential to be utilized in the industry for next generation, because most of engineering plastics having aromatic ring are available as matrix polymers, and this process is not necessary high thermal curing treatment after development.

KEY WORDS: Photosensitive Polymer / Photoacid Generator / Poly(ether ether sulfone) / Cross-linker /

High-performance engineering plastics such as polyimides (PIs), polybenzoxazoles (PBOs), poly(ether ether sulfone)s (PEESs), poly(phenylene ether)s (PPEs), and poly(ether ether keton)s (PEEKs) are continuously receiving considerable attention for their potential application in automobile, electronics, optical devices and related markets. Particularly, photosensitive polyimides (PSPIs) and polybenzoxazoles (PSPBOs) are widely used as stress buffer and insulation layers of multichip package in micro-electronics field, because they possess excellent thermal stability and mechanical properties, and reasonably low dielectric constant. ${ }^{1-3}$ As PIs and PBOs are generally not soluble in organic solvents, poly(amic acid)s (PAAs) and poly( $o$-hydroxy amide)s are used as PI and PBO precursors, respectively, and require an extremely high temperature about $350{ }^{\circ} \mathrm{C}$ to convert into corresponding PIs and PBOs. This high-temperature process is not applicable to electronic applications because the thickness of silicon wafers is less than $100 \mu \mathrm{m}$, and thus the less thermal stress is required. Therefore, we have reported a series of low temperature cyclization methods for PSPIs and PSPBOs to produce more useful applications in the micro-electronics industry. ${ }^{3-7}$ It is also important to develop a photosensitive and thermally stable polymer (PSTSP) which does not require high thermal curing treatment.

In previous papers, we reported a negative-type PSPI based on PAA, a cross-linker 4,4'-methylenebis[2,6-bis(hydroxylmethyl)]phenol (MBHP), and (5-propylsulfonyl oxyimino-5Hthiophene-2-ylidene)-2-(methylphenyl)acetonitrile (PTMA) as a PAG. ${ }^{8,9}$ A negative-type photosensitive polymer based on poly(naphthylene ether), PTMA, and hexa(methoxymethyl)melamine as a cross-linker was also reported. ${ }^{10}$ These findings prompted us to develop a PSTSP based on a common matrix such as commercially available engineering plastics, a crosslinker, and a PAG, which will provide a versatile, promising, straightforward route for the formation of PSTSP without a high thermal treatment.

This paper presents development of a negative-type chemically amplified PSPEES consisting of PEES, a cross-linker MBMP having good compatibility with PEES and DIAS as a PAG. A patterning process is shown in Scheme 1. The formulation of PSPEES is simple, involving the addition of MBMP and DIAS to a PEES solution. The PSPEES solution is spin-coated and baked in the usual way. Then, the film is exposed to UV light to produce the corresponding sulfonic acid from DIAS. Upon PEB treatment of the PEES film, the photogenerated acid catalyzes the formation of benzylic carbocations, which undergo electrophilic substitution on the aromatic rings. This reaction converts soluble PEES into insoluble cross-linked polymer. The exposed and baked film then can be developed with DMAc to provide a negativeimage.

\section{EXPERIMENTAL}

\section{Materials}

MBHP was prepared according to a previous report. ${ }^{11}$ DIAS was kindly donated by (Toyo Gousei Co., Ltd.) and used without further purification. Other reagents and solvents were used as received. PEES was purchased from SIGMA-Aldrich Co., Ltd. The number- and weight-average molecular weights $\left(M_{\mathrm{n}}\right.$ and $M_{\mathrm{w}}$ ) of PEES were 34,700 and 60,700, respectively, which estimated by GPC using polystyrene standard. 


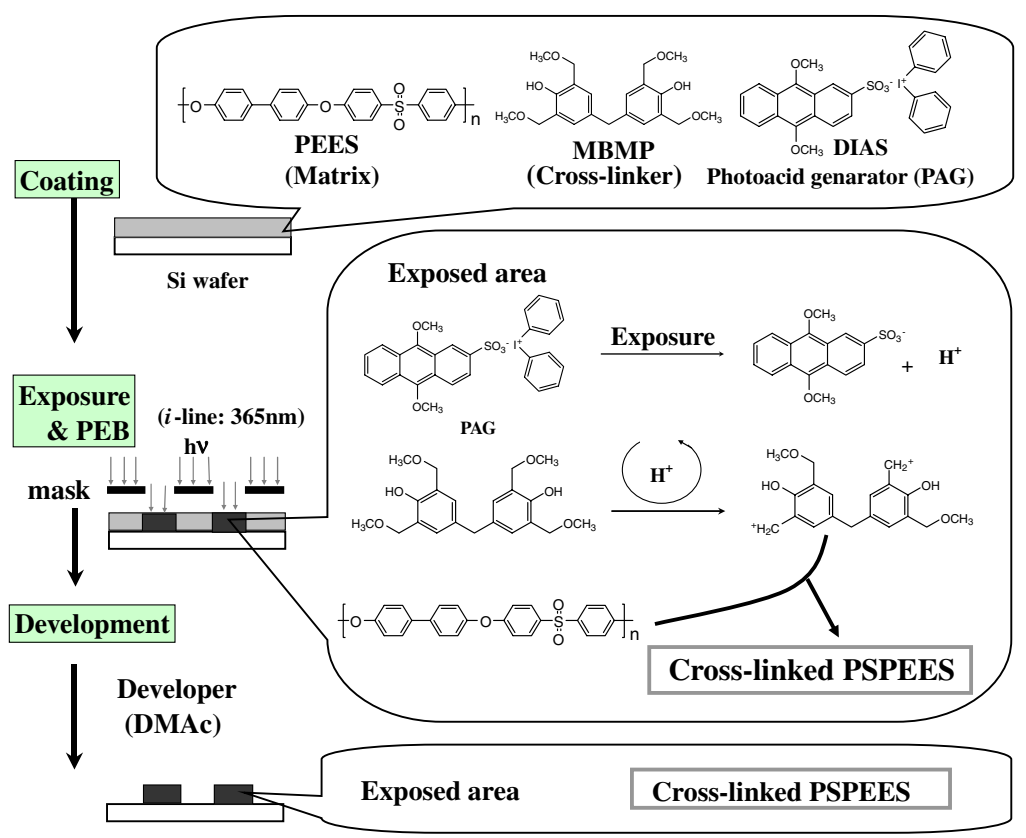

Scheme 1. Patterning process using negative-type PSPEES.

\section{Synthesis of MBMP}

MBHP $(0.500 \mathrm{~g}, 1.56 \mathrm{mmol})$ was added to anhydrous methanol $(50 \mathrm{~mL})$ containing concentrated sulfuric acid $(0.175 \mathrm{~g})$ and the solution was heated at $60^{\circ} \mathrm{C}$ for $20 \mathrm{~h}$. The resulting solution was concentrated at reduced pressure using a rotary evaporator. The crude material was extracted with dichloromethane. The organic layer was washed with $1 \mathrm{wt} \%$ sodium hydrogen carbonate aqueous solution and water, dried over magnesium sulfate, and concentrated at reduced pressure using a rotary evaporator. The crude product was purified by column chromatography eluted with ethyl acetate/hexane ( $2 / 3$ in volume ratio) to give solid. Yield: $0.511 \mathrm{~g} \mathrm{(87 \% ),} \mathrm{m.p.}$ 36.5-37.5 ${ }^{\circ} \mathrm{C}$, IR ( $\left.\mathrm{KBr}, v \mathrm{~cm}^{-1}\right)$ : 1083 and 1222 (C-O-C), 1485 and $1608(\mathrm{Ar}-\mathrm{H}), 2827\left(-\mathrm{CH}_{3}\right), 2989(\mathrm{Ar}-\mathrm{H}), 3355 \mathrm{~cm}^{-1}(\mathrm{OH})$, ${ }^{1} \mathrm{H}$ NMR ( $\left.\mathrm{CDCl}_{3}, \delta, \mathrm{ppm}\right): 3.42$ (s, $12 \mathrm{H}, \mathrm{OCH}_{3}$ ), 3.78 (s, $2 \mathrm{H}$, $\left.\mathrm{CH}_{2}\right), 4.55$ (s, 8H, $\left.\underline{\mathrm{CH}}_{2}\right), 6.92$ (s, $\left.4 \mathrm{H}, \mathrm{Ar} \underline{\mathrm{H}}\right), 7.67$ (s, $\left.2 \mathrm{H}, \mathrm{OH}\right)$. ${ }^{13} \mathrm{C}$ NMR $\left(\mathrm{CDCl}_{3}, \delta, \mathrm{ppm}\right): 40.59,58.75,72.35,123.93$, $129.22,132.89,136.16,152.94, \mathrm{E}_{\mathrm{LEM}}$. $\mathrm{A}_{\mathrm{NAL}}$. Calcd for $\mathrm{C}_{21} \mathrm{H}_{28} \mathrm{O}_{6}$ : C, $67.00 \% ; \mathrm{H}, 7.50 \%$. Found: C, $66.90 \% ; \mathrm{H}, 7.47 \%$.

\section{Dissolution Rate}

PEES was dissolved in cyclopentanone, followed by addition of MBMP $(15,10,5 \mathrm{wt} \%)$ and DIAS (5 wt \%) (solid content: $20 \mathrm{wt} \%$ ). The $2.5 \mu \mathrm{m}$ thickness of polymer films were obtained by spin-casting from the solution on a silicon wafer. These films were pre-baked at $80^{\circ} \mathrm{C}$ for $1 \mathrm{~min}$, and then exposed to a filtered super-high pressure mercury lamp at $365 \mathrm{~nm}$ wavelength light, followed by PEB at temperature $\left(130-180^{\circ} \mathrm{C}\right)$ for each time. The dissolution rate $(\AA / s)$ of the film thickness was determined from the changes in the film thickness before and after development with DMAc.

\section{Photosensitivity}

The photosensitive polymer solution was prepared by dissolving PEES, a cross-linker MBMP and DIAS as a PAG in cyclopentanone. The films were prepared by the spin-casting of this solution onto the silicon wafer, and then subjected to a successive process as follows: pre-baking at $80^{\circ} \mathrm{C}$ for $1 \mathrm{~min}$, exposure to $365 \mathrm{~nm}$ light with changing a dose, $\mathrm{PEB}$ at $170^{\circ} \mathrm{C}$ for $3 \mathrm{~min}$, and then developed with DMAc for $2 \mathrm{~s}$ at room temperature. A characteristic photosensitive curve was obtained by plotting a normalized film thickness against exposure dose (unit: $\mathrm{mJ} / \mathrm{cm}^{2}$ ). Image-wise exposure through a mask was carried out in a contact-printing mode.

\section{Preparation of PSPEES and PEES Films for Dynamic Viscoelastic Analysis}

To evaluate thermal and mechanical properties of PSPEES and PEES, their thick films (thickness: 60-65 $\mu \mathrm{m}$ ) were prepared. The PSPEES resist solution (PEES/MBMP/ DIAS: $85 / 10 / 5 \mathrm{wt} \%$, solid content: $20 \mathrm{wt} \%$ ) in cyclopentanone was cast on a glass plate. The resulting film was heated each temperature at $40,80,100$, and $135^{\circ} \mathrm{C}$ for $30 \mathrm{~min}$, then exposed with $i$-line of $1000 \mathrm{~mJ} / \mathrm{cm}^{2}$, and post-exposure baked at $170{ }^{\circ} \mathrm{C}$ for $15 \mathrm{~min}$. The PEES film on a glass plate was heated each temperature at $40,80,100$, and $135^{\circ} \mathrm{C}$ for $30 \mathrm{~min}$, dried at $60^{\circ} \mathrm{C}$ under reduced pressure for $2 \mathrm{~h}$, and then at $170^{\circ} \mathrm{C}$ for $1 \mathrm{~h}$.

\section{Measurement}

The ${ }^{1} \mathrm{H}$ and ${ }^{13} \mathrm{C}$ NMR spectra were obtained on a BRUKER DPX-300 spectrometer at ${ }^{1} \mathrm{H}, 300 \mathrm{MHz}$ and ${ }^{13} \mathrm{C}, 75 \mathrm{MHz}$. Deuterated chloroform was used as a solvent with tetramethyl silane as an internal standard. Number- and weight-average molecular weights $\left(M_{\mathrm{n}}\right.$ and $\left.M_{\mathrm{w}}\right)$ were estimated by a gel 
permeation chromatograph (GPC) on a Jasco co-2065 Plus system equipped with a polystyrene gel column (TOSOH TSKgel $\mathrm{GMH}_{\mathrm{HR}}-\mathrm{M}$ ) eluted with $N, N$-dimethylformamide (DMF) at a flow rate of $1.0 \mathrm{~mL} / \mathrm{min}$ calibrated by standard polystyrene samples. The film was spin-coated on a silicon wafer from the polymer solution in cyclopentanone, and the film thickness was measured by Veeco Instrument Dektak ${ }^{3}$ surface profiler. UV-visible spectra on quartz substrate were recorded on Horiba JASCO V-560 spectrometer. The scanning electron microscopic image (SEM) was taken by a Technex Lab. Tiny-SEM 1540 with $5 \mathrm{kV}$ accelerating voltage. Dynamic mechanical thermal analysis (DMA) was performed on PEES and PSPEES film specimens (30 mm long, $10 \mathrm{~mm}$ wide, and $60-65 \mu \mathrm{m}$ thick) on a Seiko DMS 6300 at a heating rate of $2{ }^{\circ} \mathrm{C} / \mathrm{min}$ with a load frequency of $1 \mathrm{~Hz}$ in air. The glass transition temperatures $\left(T_{\mathrm{g}} \mathrm{s}\right)$ are determined as the peak temperatures of the loss modulus $\left(E^{\prime \prime}\right)$ plot.

\section{RESULTS AND DISCUSSION}

\section{Synthesis of MBMP}

In previous papers, MBHP was used as a cross-linker, ${ }^{8,9}$ however, it did not mix well with PEES as a matrix polymer. Thus, a cross-linker MBMP, which is a less polar compound than MBHP, was prepared by methoxylation of MBHP (Scheme 2). MBMP is soluble in cyclopentanone, DMAc, toluene, and chloroform. A clear transparent film could be spincoated on a silicon wafer from a solution of PEES and MBMP in cyclopentanone.

\section{Lithographic Evaluation of PSPEES}

Commercially available PEES was chosen as a matrix. As no absorption in the UV-vis spectrum of PEES was observed above $320 \mathrm{~nm}$, PTMA having an strong absorption extending to $450 \mathrm{~nm}$ and a decomposition temperature at around $140^{\circ} \mathrm{C}$ was first used as a PAG. ${ }^{12}$ However, the PEB temperature higher than $140{ }^{\circ} \mathrm{C}$ was required because of the high glass transition temperature $\left(T_{\mathrm{g}}\right)$ of PEES. Thus, DIAS having a strong absorption at $365 \mathrm{~nm}$ as well as high thermal stability up to $180^{\circ} \mathrm{C}$ in the air was selected as a PAG. ${ }^{13-15}$

The photosensitive polymer system consisting of PEES, MBMP, and DIAS was formulated. The film spin-cast on a silicon wafer was prepared, exposed a filtered super-highpressure mercury lamp ( $365 \mathrm{~nm}$ : $i$-line), and developed with DMAc at room temperature. The dissolution rate was calculated by measuring the change of the film thickness before and after development.

Prior to the lithographic evaluation of PSPEES, the transparency of the PEES film in the UV-visible region and the

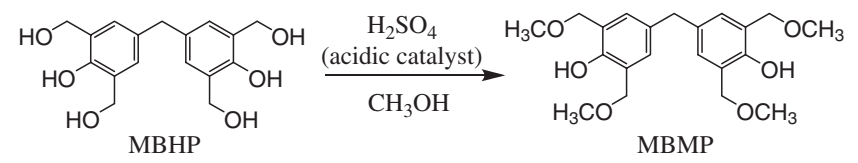

Scheme 2. Synthesis of MBMP (a novel cross-linker) from MBHP.

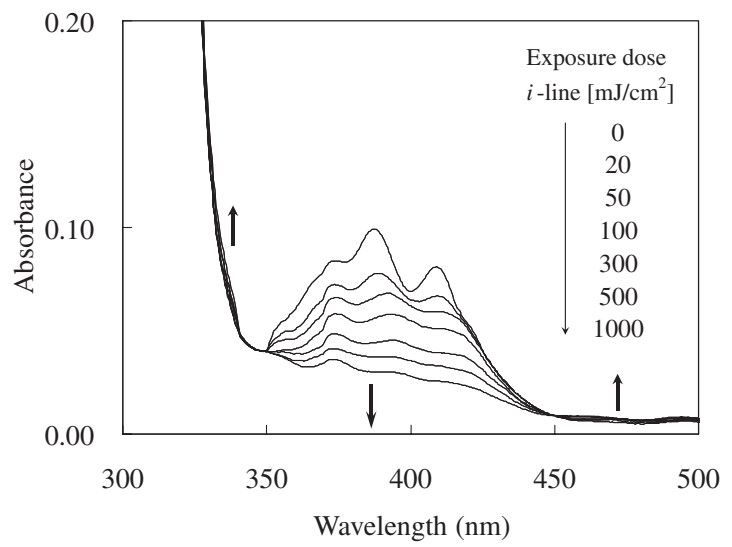

Figure 1. Change of UV-visble spectra of DIAS [5 wt \% $(3.3 \mathrm{~mol} \%)$ relative to PEES] in $1.7 \mu \mathrm{m}$ PEES film on the quartz substrate due to $365 \mathrm{~nm}$ light irradiation.

sensitivity of DIAS in this resist were investigated. The $2.5 \mu \mathrm{m}$ PEES film was completely transparent over $350 \mathrm{~nm}$. The changes of the UV-visible spectrum of the PEES film containing $5 \mathrm{wt} \%$ ( $3.3 \mathrm{~mol} \%)$ DIAS upon UV irradiation is shown in Figure 1. The absorption bands at 370, 386, and $408 \mathrm{~nm}$ of DIAS decrease rapidly upon irradiation, and a half amount of DIAS decomposes after exposure to $100 \mathrm{~mJ} / \mathrm{cm}^{2}$, which indicates that the acid of $1.6 \mathrm{~mol} \%$ to the matrix is generated. This amount of the acid will be enough to form a cross-linking polymer in the chemically amplified resists, where a single photochemical event induces a cascade of chemical reactions. ${ }^{16}$

The PEB temperature is crucial for the chemically amplified resist system because the diffusion of the acid generated from PAG after $i$-line exposure in the film is an important key factor. Thus, the effect of PEB temperature on the dissolution rate in DMAc was investigated, where each film was pre-baked at $80^{\circ} \mathrm{C}$ for $1 \mathrm{~min}$ in the air, exposed to $300 \mathrm{~mJ} / \mathrm{cm}^{2}$ of $i$-line, and then post-exposure baked at each temperature for $3 \mathrm{~min}$. The results are shown in Figure 2. By changing the PEB temperature from 130 to $180^{\circ} \mathrm{C}$, a very high dissolution contrast (DC) (over 8,000 times) is obtained in the temperature range of between 160 and $180^{\circ} \mathrm{C}$. Hence, the acid generated from PAG diffuses effectively in the film at around $160^{\circ} \mathrm{C}$ and accelerates the cross-linking reaction. This behavior can be supported by DMA analysis as described later section, that is, the storage modulus $E^{\prime}$ of the film starts to decrease at around $160^{\circ} \mathrm{C}$ and the loss modulus $E^{\prime}$ of the film also begins to increase at this temperature.

The diffusion length of a photo-generated acid is also influenced by a PEB time. Figure 3 shows the effect of the PEB time on the dissolution rate of the films $\mathrm{PEB}$ at $160{ }^{\circ} \mathrm{C}$ in DMAc. A DC reaches approximately 9,800 times after $12 \mathrm{~min}$, which is a long PEB time for the process. A higher PEB temperature will bring about a considerable reduction of the PEB time due to the accelerated diffusion length of the photogenerated acid. The results are depicted in Figure 4, indicating that only $3 \mathrm{~min}$ is enough to get a high DC at the PEB 


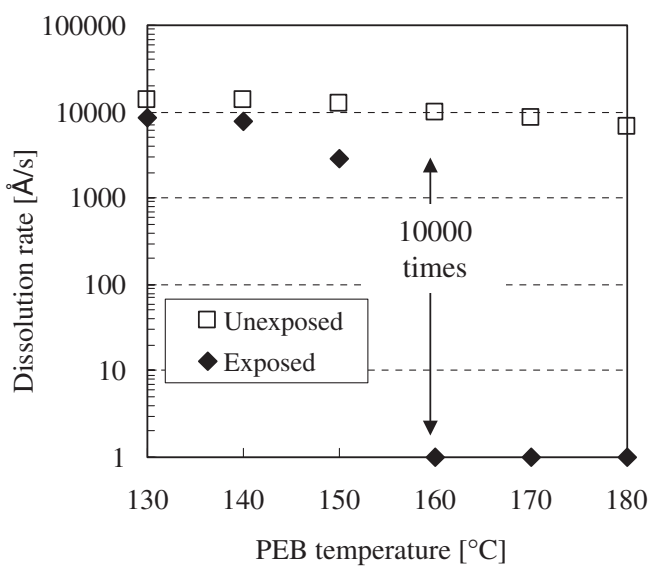

Figure 2. Effect of PEB temperature on the dissolution rate for the PSPEES films (PEES/MBMP/DIAS:80/15/5 wt \%) in the exposed ( ) and unexposed areas $(\square)$. The $i$-line exposure and PEB time were fixed at $300 \mathrm{~mJ} / \mathrm{cm}^{2}$ and $3 \mathrm{~min}$, respectively, and developed in DMAc for $2 \mathrm{~s}$.

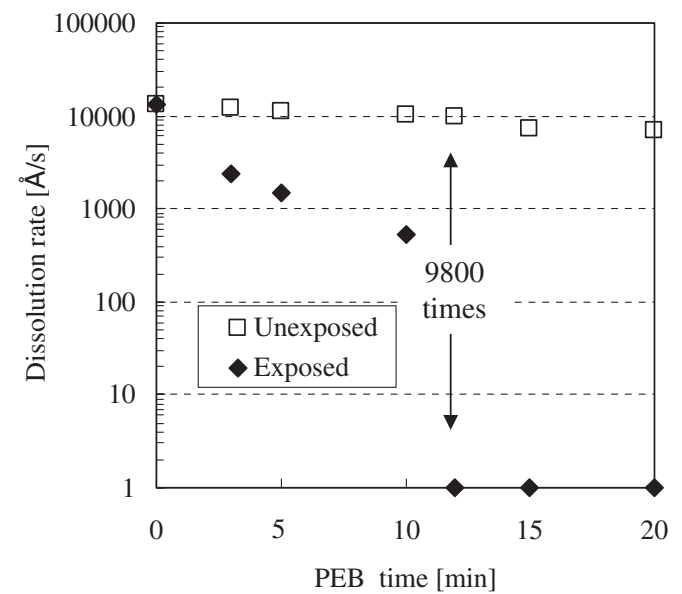

Figure 3. Effect of PEB time at $160^{\circ} \mathrm{C}$ on the dissolution rate for the PSPEES films (PEES/MBMP/DIAS:85/10/5 wt \%) in the exposed $(\checkmark)$ and unexposed areas $(\square)$. The $i$-line exposure and development time were fixed at $300 \mathrm{~mJ} / \mathrm{cm}^{2}$ and $2 \mathrm{~s}$, respectively.

temperature of $170{ }^{\circ} \mathrm{C}$. In addition, to determine a minimum amount of MBMP at $170{ }^{\circ} \mathrm{C}$, the effect of MBMP loading was investigated with a $5 \mathrm{wt} \%$ DIAS loading. The results shown in Figure 5 indicate that a $10 \mathrm{wt} \%$ MBMP loading is necessary to get a high DC. Scheme 3 shows a possible acid-catalyzed cross-linking mechanism for the PSPEES resist, which is similar to that for the negative-type PSPI based on PAA, MBHP, and PAG. ${ }^{9}$ The self-condensation of MBMP occurs mainly, and the cross-linking reaction between MBMP and PEES, which changes the solubility of the PSPEES resist to DMAc, is a minor one. Thus, a relatively large amount of MBMP loading is required. Under these conditions, the extent of the acid-catalyzed cross-linking reaction was studied. The exposed films were immersed in DMAc for $1 \mathrm{~h}$ at room temperature. The weight of developed films was almost same as that of the exposed films, which indicates that the crosslinking reaction proceeded effectively, giving the completely

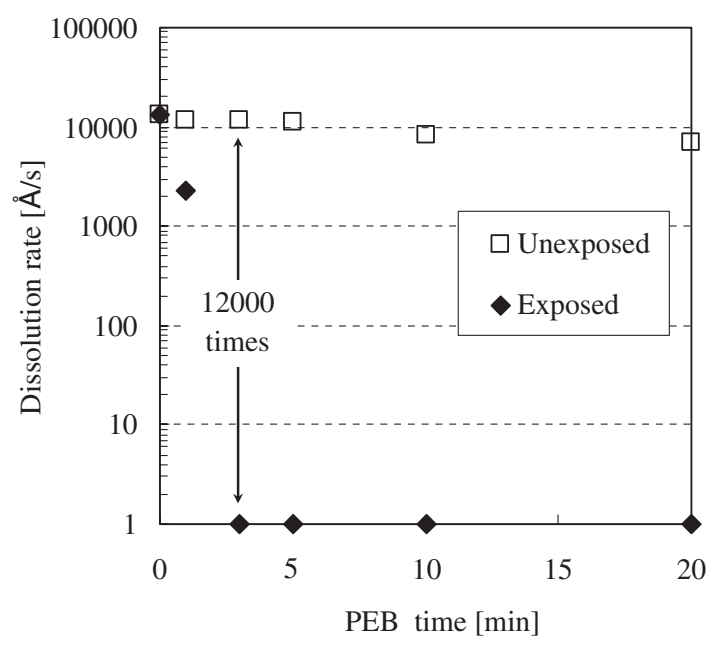

Figure 4. Effect of $P E B$ time at $170^{\circ} \mathrm{C}$ on the dissolution rate for the PSPEES films (PEES/MBMP/DIAS:85/10/5 wt \%) in the exposed $(\diamond)$ and unexposed areas $(\square)$. The $i$-line exposure and development time were fixed at $300 \mathrm{~mJ} / \mathrm{cm}^{2}$ and $2 \mathrm{~s}$, respectively.

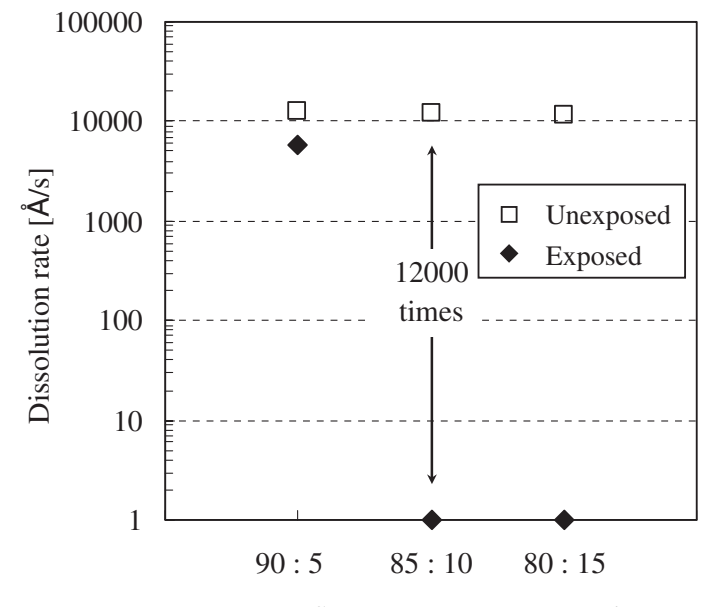

PEES : MBMP content [wt \%]

Figure 5. Effect of MBMP loading on PEES at $170^{\circ} \mathrm{C}$ for $3 \mathrm{~min}$ on the dissolution rate for the PSPEES films (DIAS: $5 \mathrm{wt} \%$ ) in the exposed $(\diamond)$ and unexposed areas $(\square)$. The $i$-line exposure and development time in DMAc were fixed at $300 \mathrm{~mJ} / \mathrm{cm}^{2}$ and $2 \mathrm{~s}$, respectively.

insoluble PSPEES films in DMAc. On the basis of the findings described above, a resist system consisting of PEES (85 wt \%: $85.9 \mathrm{~mol} \%$ ), MBMP (10 wt \%: $10.8 \mathrm{~mol} \%$ ), and DIAS (5 wt \%: $3.3 \mathrm{~mol} \%$ ) was formulated. The sensitivity curve of a $2.5 \mu \mathrm{m}$ resist film (Figure 6) indicates the high sensitivity $\left(\mathrm{D}_{0.5}\right)$ of $21 \mathrm{~mJ} / \mathrm{cm}^{2}$ and the good contrast $\left(\gamma_{0.5}\right)$ of 2.1 , respectively. This PSPEES resist has 5 to 15 times higher sensitivity as compared to common PSPBO resists in the market, which are based on poly(o-hydroxy amide) and diazonaphtoquinone (DNQ) ${ }^{17}$ The high sensitivity of PSPEES is explained by the high transparency of PEES in the $i$-line region and the introduction of a chemically amplified system.

Next, Figure 7 represents a SEM image of a contact-printed pattern after exposure of $i$-line through a photo-mask. The 
<smiles>COc1c2ccccc2c(OC)c2cc([Se][Te](c3ccccc3)c3ccccc3)ccc12</smiles><smiles>[3H]CCCOCc1cc(CCc2cc(Cc3cc(COC)c(O)c(COC)c3)cc(COC)c2O)cc(COC)c1O</smiles><smiles>CCOCc1cc(Cc2cc(COC)c(O)c(Cc3cc(COC)c(O)c(COC)c3Cc3cc(COC)cc(COC)c3Cc3cc(COC)cc(COC)c3O)c2)cc(COC)c1O</smiles>

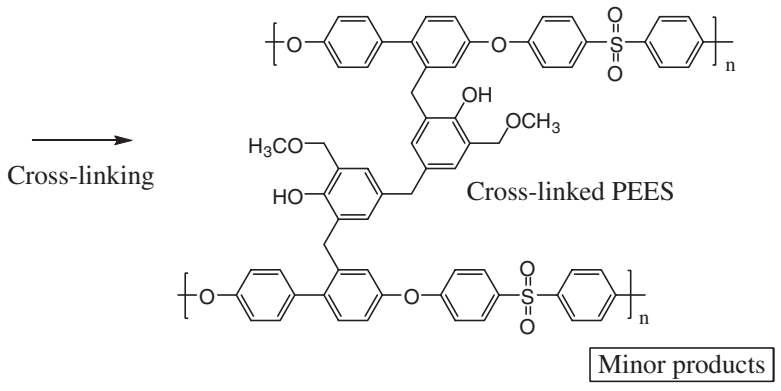

Scheme 3. Mechanism of the acid-catalyzed cross-linking reaction.

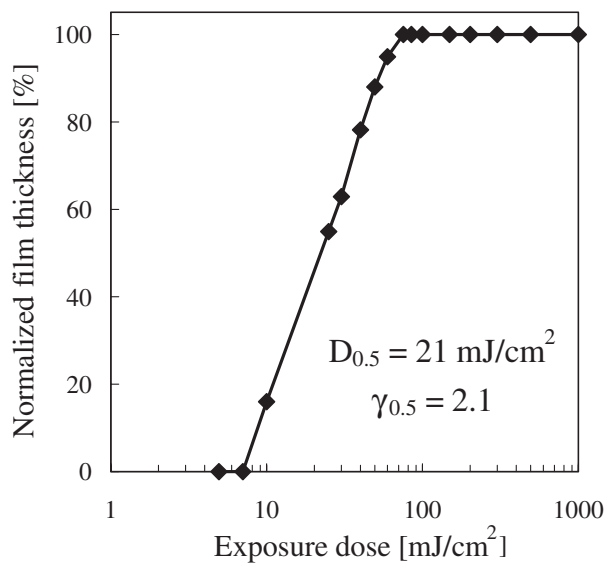

Figure 6. Characteristic photosensitive curve for the PSPEES films (PEES/ MBMP/DIAS:85/10/5 wt \%). The PEB temperature, PEB time, and development time were fixed at $170^{\circ} \mathrm{C}, 3 \mathrm{~min}$, and $2 \mathrm{~s}$, respectively. $D_{0.5}$ is the sensitivity, and $\gamma_{0.5}$ is the contrast.

resist is capable of resolving a $4 \mu \mathrm{m}$ feature when a $2.5 \mu \mathrm{m}$ thickness film was used. The high resolution of PSPEES resist may be attributed to the very large DC between the unexposed and the exposed area after irradiation.

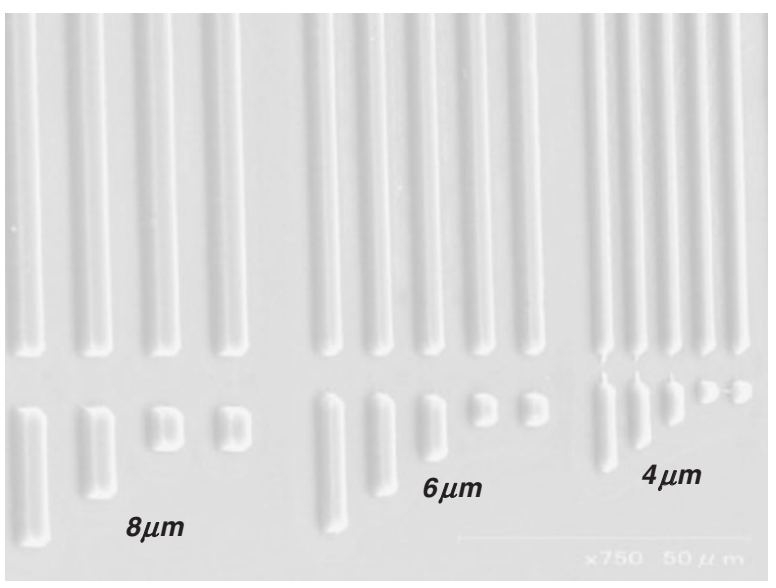

Figure 7. SEM image of negative-pattern (PEES/MBMP/DIAS:85/10/ $5 \mathrm{wt} \%)$. The lithographic condition was as follows: $20 \mathrm{wt} \%$ solid content solution in cyclopentanone was spin-coated, prebaked at $80^{\circ} \mathrm{C}$ for $1 \mathrm{~min}$, exposed $150 \mathrm{~mJ} / \mathrm{cm}^{2}$ of $i$-line, post-exposure baked at $170^{\circ} \mathrm{C}$ for $3 \mathrm{~min}$, developed with DMAc for $15 \mathrm{~s}$ at room temperature (film thickness: $2.5 \mu \mathrm{m}$ ).

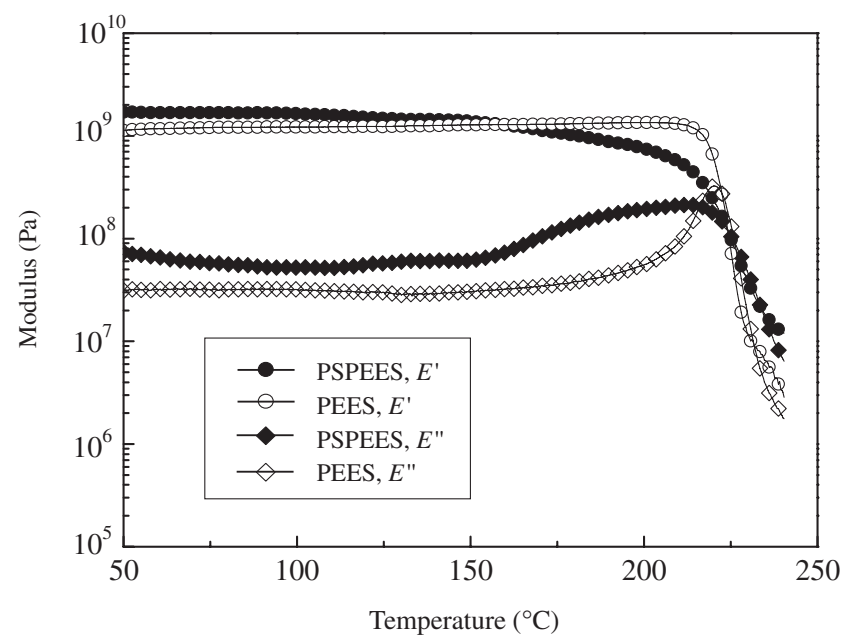

Figure 8. DMA curves (storage modulus $E^{\prime}$ and loss modulus $E^{\prime \prime}, 1 \mathrm{~Hz}$, $2{ }^{\circ} \mathrm{C} / \mathrm{min}$, in air) of PEES and PSPEES (PEES/MBMP/DIAS:85/ $10 / 5 \mathrm{wt} \%$ ) films after an $i$-line exposure of $1000 \mathrm{~mJ} / \mathrm{cm}^{2}$, post exposure-baked at $170^{\circ} \mathrm{C}$ for $15 \mathrm{~min}$.

\section{Thermal and Mechanical Properties of PSPEES Film}

Figure 8 shows the DMA curves of PEES and PSPEES films measured at the loading frequency of $1 \mathrm{~Hz}$. The initial storage moduli $\left(E^{\prime}\right)$ of PEES and PSPEES at $50{ }^{\circ} \mathrm{C}$ are 1.0 and $1.7 \mathrm{GPa}$, respectively, indicating the good mechanical properties of the polymers. The $E^{\prime}$ of PSPEES becomes low as compared to that of PEES at around $160{ }^{\circ} \mathrm{C}$ probably because of the mixture of MBMP, DIAS, and PEES. However, PSPEES retains its mechanical properties up to around $225^{\circ} \mathrm{C}$. The $T_{\mathrm{g}} \mathrm{s}$ of PEES and PSPEES determined as the peak temperature of the $E^{\prime \prime}$ plots show the same temperature of $225^{\circ} \mathrm{C}$, which is consistent with the mechanical loss temperature of both polymers. These results suggest that the extent of cross-linking is so low that the thermal and mechanical properties do not change. 


\section{CONCLUSIONS}

A novel cross-linker MBMP has excellent compatibility with PEES and has the good advantage of formulating PSPEES based on PEES, MBMP, and DIAS compared to the other cross-linker such as MBHP. The PSPEES consisting of PEES (85 wt \%), MBMP (10wt \%) and DIAS (5 wt \%) showed the high sensitivity $\left(D_{0.5}\right)$ of $21 \mathrm{~mJ} / \mathrm{cm}^{2}$ and the contrast $\left(\gamma_{0.5}\right)$ of 2.1 , respectively. After the optimization of photolithographic processes, a clear negative pattern with a $4 \mu \mathrm{m}$ resolution was obtained in a $2.5 \mu \mathrm{m}$ film. This PSPEES formulation method combining MBMP and DIAS could be applied for development of PSTSPs based on other engineering plastics such as poly(phenylene ether), poly(ether ether ketone), and polycarbonate as a matrix.

Acknowledgment. This work was financially supported by a Grant-in-Aid for Science Research (No. 18350059) from the Japanese Ministry of Education, Science, Sports, and Culture, which is gratefully acknowledged.

Received: January 11, 2008 Accepted: April 7, 2008

Published: May 28, 2008

\section{REFERENCES AND NOTES}

1. In "Polyimides fundamentals and applicatuion" M. K. Ghosh and K. L. Mittal, Ed., M. Dekker, New York, 1996, p121.

2. "Photosensitive Polyimide: Fundamental and Applications" K. Horie and T. Yamashita, Ed., Technomic, Lancasteer, 1995.

3. K. Fukukawa and M. Ueda, Polym. J., 38, 405 (2006).

4. K. Fukukawa, Y. Shibasaki, and M. Ueda, Chem. Lett., 33, 1156 (2004).

5. K. Fukukawa, Y. Shibasaki, and M. Ueda, Polym. Adv. Technol., 17, 131 (2006).

6. K. Mizoguchi, Y. Shibasaki, and M. Ueda, J. Photopolym. Sci. Technol., 20, 181 (2007).

7. K. Fukukawa and M. Ueda, Macromolecules, 39, 2100 (2006).

8. Y. Watanabe, Y. Shibasaki, S. Ando, and M. Ueda, Polym. J., 37, 270 (2005).

9. Y. Watanabe, K. Fukukawa, Y. Shibasaki, and M. Ueda, J. Polym. Sci., Part A: Polym. Chem., 43, 593 (2005).

10. K. Tsuchiya, Y. Shibasaki, and M. Ueda, Polym. J., 39, 442 (2007).

11. N. Takeda and E. Ishimura, Jpn. Kokai, Tokkyo Koho, 1983, JP 58, 116, 433.

12. T. Asakura, H. Yamamoto, and M. Ohwa, J. Photopolym. Sci. Technol., 13, 223 (2000).

13. K. Nitoh, T. Yamaoka, and A. Umehara, Chem. Lett., 1869 (1991).

14. K. Naitoh, K. Kanai, and Y. Yamaoka, J. Photopolym. Sci. Technol., 4, 411 (1991).

15. The thermal stability of DIAS was evaluated by thermogarvimetric analysis.

16. H. Ito, Adv. Polym. Sci., 172, 37 (2005).

17. D. N. Khanna and W.-H. Mueller, Polym. Eng. Sci., 29, 954 (1989). 